\title{
Socioeconomic and intraoral polarization of untreated caries and tooth loss among male adolescents
}

\author{
Priscila STONA $^{(a)}$ \\ Paulo Floriani KRAMER(b) \\ Fabiana VARGAS-FERREIRA(c) if \\ Lívia Mund de AMORIM(b) iD \\ Elisa Maria de Rosa \\ Barros COELHO(b) ID \\ Carlos Alberto FELDENS(b) \\ (a)Faculdade da Serra Gaúcha - FSG, School \\ of Dentistry, Department of Pediatric \\ Dentistry. Caxias do Sul, RS, Brazil. \\ (b) Universidade Luterana do Brasil - Ulbra, \\ School of Dentistry, Department of Pediatric \\ Dentistry. Porto Alegre, RS, Brazil. \\ (c) Universidade Federal de Minas Gerais - \\ UFMG, School of Dentistry, Department of \\ Community and Preventive Dentistry. Belo \\ Horizonte, MG, Brazil.
}

Declaration of Interests: The authors certify that they have no commercial or associative interest that represents a conflict of interest in connection with the manuscript.

Corresponding Author:

Carlos Alberto Feldens

E-mail: cafeldens@gmail.com

Submitted: June 4, 2020

Accepted for publication: October 22, 2020

Last revision: November 26, 2020

\begin{abstract}
The aim of this study was to investigate the intraoral distribution of untreated caries and tooth loss and estimate the impact of different socioeconomic factors on the occurrence of these outcomes. A cross-sectional study was conducted with 652 18-yearold male adolescents from the city of Sapucaia do Sul, Brazil, who conscripted for military service. The participants answered a questionnaire addressing sociodemographic variables. Two trained and calibrated examiners performed the clinical examinations for the diagnosis of dental caries using the criteria of the World Health Organization. Tooth group and adolescent were the units of analysis for the primary outcomes of the study. Poisson regression analysis with robust variance was performed, with the calculation of crude and adjusted prevalence ratios (PR) and 95\% confidence intervals (CI). The prevalence of caries experience and untreated caries was $70.2 \%$ and $39.3 \%$, respectively, and $9.4 \%$ of the adolescents had missing teeth. Sixty-seven percent of the untreated caries and $98.8 \%$ of missing teeth were in first molars. The probability of dental caries and tooth loss was significantly higher among adolescents with less schooling (PR $=2.56 ; 95 \% \mathrm{CI}$ : 1.97-3.32 and PR = 3.28; 95\%CI: 1.61-6.65, respectively) and those whose mothers had less schooling ( $\mathrm{PR}=1.31$; 95\%CI: 1.03-1.67 and PR $=2.30 ; 95 \% \mathrm{CI}: 1.18-4.50$, respectively). In conclusion, the occurrence of untreated dental caries and tooth loss was concentrated in the first molars of adolescents. Moreover, the prevalence of both conditions was higher among adolescents with low schooling and whose mothers had low schooling, reflecting the strong intraoral and socioeconomic polarization of these outcomes.
\end{abstract}

Keywords: Adolescent; Dental Caries; Tooth Loss.

\section{Introduction}

Untreated caries on permanent teeth is the most prevalent condition among all diseases, affecting 2.5 billion people throughout the world. ${ }^{1,2}$ One of the most serious consequences of untreated caries is tooth loss, which is a progressive condition that reflects the oral health history of individuals and their access to health services. ${ }^{3,4,5}$ Tooth loss is an important determinant of perceived overall health as well as a strong marker of both oral health and social inequality., ${ }^{4,6,6,7}$ 
Studies are consistent in reporting functional, esthetic, and emotional problems stemming from untreated caries and tooth loss, exerting a significant impact on oral health-related quality of life as well as both direct and indirect costs to families and society. ${ }^{8,910,11}$ Severe tooth loss is the oral condition that most accounts for disability-adjusted life years (DALYs), which is a measure of years lost due to ill-health and disability. Moreover, severe tooth loss accounts for two-thirds of the overall loss of productivity due to dental diseases. ${ }^{2,11}$

One of the goals established by the World Health Organization for the year 2020 was to reduce the number of teeth extracted due to dental caries at 18 years of age $\mathrm{e}^{12}$ However, the accentuated incidence of untreated dental caries and tooth loss in the school phase and adolescence in the majority of countries ${ }^{2}$ demonstrates that preventive oral health policies have not been effective. In Brazil, caries experience increases from $43.5 \%$ to $76.1 \%$ during adolescence, affecting $99 \%$ of Brazilians between the ages of 35 and 44 years. ${ }^{13}$

A combination of preventive population-based and individual approaches is key to reducing the burden of dental caries and tooth loss. The distribution of these outcomes both intraorally and in the population needs to be considered so that available resources can be used rationally. ${ }^{14}$ Although it is well known that dental caries and tooth loss are closely linked to socioeconomic status, ${ }^{4,8,15,16,17}$ few studies have evaluated this association at 18 years of age and have generally investigated the role of family income. ${ }^{18}$ During the transition from adolescence to adulthood, schooling and entering the job market are fundamental variables for health. ${ }^{19}$ To the best of our knowledge, however, no study has investigated gradients of dental caries and tooth loss in this age group considering such characteristics. The clarification of this issue could provide a more precise definition of the social gradient for the planning of social and health policies.

Some studies have described the intraoral distribution of dental caries and tooth loss. However, such investigations in the first decades of life are scarce and restricted to 12-year-old children or individuals in the intermediate phase of adolescence and no study has investigated the intraoral distribution of both outcomes. Preventive strategies based on the individual should consider that the first few years after tooth eruption is the period with the highest risk of caries incidence. ${ }^{20}$ Thus, knowing the most affected teeth could contribute to the establishment of specific protection measures for different age groups, thereby reducing health care costs and avoiding or reducing the impact on quality of life. .1,21,22 $^{2}$

Therefore, the aim of the present study was to investigate the intraoral distribution of untreated caries and tooth loss and estimate the impact of different socioeconomic factors on the occurrence of these outcomes in 18-year-old male adolescents in a city in southern Brazil.

\section{Methodology}

\section{Study design and sample size}

A cross-sectional census study was conducted with 18-year-old male adolescents in Sapucaia do Sul, which is a city in southern Brazil. The study population was adolescents who conscripted in the Brazilian Army in 2017, which is mandatory for all males who complete 18 years of age each year. Sapucaia do Sul has an estimated population of 138,000 residents and all houses have a fluoridated water supply. The Human Development Index of the city is high (HDI = 0.726) and within the range for the southern region of the country. The only inclusion criterion was being 18 years old at the time of data collection. Among a total of 1,043 conscripts aged 17 and 20 years, 658 were 18 years old. Of them, six refused to participate.

The sample size for the present study was determined by the number of 18 -year-olds conscripted in the army in the city in the year in which data collection occurred. The sample power was calculated based on an estimate of 60018 -year-old adolescents conscripted the previous year. This sample size had a power $>83 \%$ to detect a difference in the prevalence of tooth loss and dental caries among adolescents with a lower and higher socioeconomic status with a 95\% confidence level according to the following parameters: tooth loss of $9.0 \%$ versus $3.0 \%{ }^{23}$ dental caries of $51.6 \%$ versus $31.1 \% .^{24}$ 


\section{Data collection}

The data were collected through a questionnaire and dental clinical examination. The questionnaire was administered by five trained interviewers and addressed previous dental visits, schooling of the adolescent (in complete years of study), paid employment (yes or no), mother's schooling (in complete years of study), and family income (in Brazilian currency). Considering the significant difference between adolescent's schooling and mother's schooling, different cutoff points were established for these two variables (adolescent's: $\leq 8,9-10$, or $\geq 11$ years; mother's: $\leq 5,6-8$ or $>8$ years). The cutoff points for schooling were defined based on the stages of the Brazilian educational system ${ }^{7}$ and the distribution of frequencies to maintain the power to capture relevant differences between categories. Family income was categorized based on the Brazilian monthly minimum wage (BMMW; $<2$ times, $2-3$ times or $>3$ times the BMMW), which corresponded to approximately 292 US dollars during the data collection period.

The adolescents were clinically examined by two examiners (students of the PhD Program in Dentistry, with previous experience in oral health surveys). The training and calibration process lasted 30 hours. It was done prior to the onset of the data collection process, and included theoretical activities, practical activities, and discussions of the criteria for the diagnosis of dental caries under the guidance of an experienced epidemiologist. For calibration, twenty 18-year-old male adolescents that were not participants of the study were examined. Weighted Kappa values for intra-examiner and inter-examiner reproducibility ranged from 0.91 to 0.95 and 0.84 to 0.86 , respectively, for the diagnosis. The criteria of the World Health Organization were used for the determination of dental caries experience, with the recording of the number of decayed, missing and filled teeth (DMFT index). ${ }^{25}$ After brushing and drying the teeth, the examinations were performed under artificial light with the aid a WHO probe and dental mirror. The primary outcomes were the occurrence of untreated caries (D component of the DMFT index) and missing teeth due to caries (M component).

\section{Data analysis}

The statistical analyses were performed using Statistical Package for the Social Sciences, version 20.0 (IBM Statistics Inc, Chicago, USA). Simple and relative frequencies were first described for untreated caries and tooth loss according to the socioeconomic variables analyzed. Poisson regression analysis with robust variance was performed to estimate crude and adjusted prevalence ratios (PR) and 95\% confidence intervals (CI) for the occurrence of the two outcomes in the different categories of the independent variables. The three socioeconomic variables were incorporated into the multivariate model of both outcomes, regardless of the level of significance. Next, the D and M components of the DMFT index were described per tooth and simple and relative frequencies of the components of the index were described per tooth group and arch (upper and lower).

\section{Ethical aspects}

This study received approval from the Human Research Ethics Committee of the Universidade Luterana do Brazil (certificate number: 702.895) and was conducted in accordance with the guidelines established by the Declaration of Helsinki. The adolescents agreed to participate by signing a statement of informed consent prior to beginning the data collection process.

\section{Results}

The final sample was composed of 652 adolescents with schooling ranging from two to 12 years, with a mean (SD) of 9.4 (2.0) years, and $65.0 \%$ had paid employment. Mean (SD) mother's schooling was 7.9 (2.8) years and mean (SD) family income was R\$ 765 (540) US dollars, which corresponds to approximately 2.6 times the BMMW. A total of $9.4 \%$ of the adolescents had never been to a dentist and $33.4 \%$ last visited a dentist more than one year before.

Approximately $70 \%$ of the adolescents had caries experience (458/652). The DMFT index ranged from 0 to 14 , with a mean (SD) of 2.4 (2.5) and a median $\left(25^{\text {th }}-75^{\text {th }}\right.$ percentiles $)$ of $2.0(0-4)$ decayed, missing and filled teeth. The prevalence of untreated caries 
was 39.3\% (256/652) and was unequally distributed among the socioeconomic strata evaluated. The prevalence was significantly higher among adolescents with less schooling, in those whose mothers had less schooling, and in those from families with a lower income. In the multivariate model, the probability of having untreated caries was $31 \%$ higher when the mother had up to five years of schooling $(p=0.025)$, 2.6 times higher when the adolescent had less than eight years of schooling ( $p<0.001)$, and $59 \%$ higher among adolescents with eight to ten years of schooling $(\mathrm{p}<0.001)$ compared to those with at least 11 years of schooling (Table 1).

The prevalence of tooth loss was 9.4\% (61/652). Forty-five adolescents had one missing tooth, 12 had two missing teeth, and four had three missing teeth, for which a strong socioeconomic gradient was also found. The probability of tooth loss was significantly higher among adolescents with less schooling and in those whose mothers had less schooling. After adjusting for confounding variables, independent effects were found for both mother's schooling and adolescent's schooling. The probability of tooth loss was 2.3 times higher among adolescents whose mothers had less schooling $(p=0.015)$ and 3.3 times higher among adolescents with less schooling $(p=0.001)$ compared to the higher schooling categories (Table 2). Paid employment among the adolescents and family income were not associated with either of the outcomes after adjusting for the other variables.

Of the 458 adolescents with caries experience, $415(90.6 \%)$ had caries experience on the first permanent molar, $228(35.0 \%)$ on the second permanent molar, and only $12(2.6 \%)$ had no caries experience on any molars.

Figure displays the distribution of caries experience per tooth. A total of 1,529 teeth had caries experience: 565 teeth $(36.9 \%)$ had untreated caries, 81 teeth $(5.3 \%)$ were missing due to caries, and 883 teeth $(57.8 \%)$ had been filled. A strong concentration of caries was found in the first molars, followed by the second molars.

The distribution per tooth group demonstrated a concentration of untreated caries in lower first molars (35.6\%), upper first molars (21.6\%), and lower second molars (20.0\%). Only $7 \%$ of untreated caries were in the anterior teeth. Tooth loss occurred nearly exclusively in first molars $(98.8 \%)$, especially lower first molars $(84.0 \%)$ (Table 3$)$.

Table 1. Prevalence, crude and adjusted prevalence ratios (PR) and $95 \%$ confidence intervals for untreated dental caries in male adolescents from southern Brazil.

\begin{tabular}{|c|c|c|c|c|c|c|c|c|c|}
\hline \multirow{2}{*}{ Variables } & \multirow{2}{*}{$\mathrm{n}$} & \multicolumn{2}{|c|}{ Untreated caries } & \multicolumn{3}{|c|}{ Crude model } & \multicolumn{3}{|c|}{ Adjusted model } \\
\hline & & $\mathrm{n}$ & $(\%)$ & PR & $95 \% \mathrm{Cl}$ & $p$-value & PR & $95 \% \mathrm{Cl}$ & $\mathrm{p}$-value \\
\hline \multicolumn{10}{|c|}{ Mother's schooling (years) } \\
\hline$\leq 5$ & 172 & 82 & $(47.7)$ & 1.58 & $(1.24,2.01)$ & 0.000 & 1.31 & $(1.03,1.67)$ & 0.025 \\
\hline $6-8$ & 184 & 80 & $(43.5)$ & 1.44 & $(1.13,1.85)$ & 0.003 & 1.29 & $(1.01,1.64)$ & 0.042 \\
\hline$>8$ & 269 & 81 & $(30.1)$ & 1.00 & & & 1.00 & & \\
\hline \multicolumn{10}{|c|}{ Family income (BMMW) } \\
\hline$<2$ & 142 & 65 & $(45.8)$ & 1.28 & $(1.01,1.62)$ & 0.043 & 1.03 & $(0.81,1.30)$ & 0.820 \\
\hline $2-3$ & 228 & 90 & $(39.5)$ & 1.10 & $(0.88,1.38)$ & 0.395 & 0.95 & $(0.76,1.19)$ & 0.662 \\
\hline$>3$ & 282 & 101 & (35.8) & 1.00 & & & 1.00 & & \\
\hline \multicolumn{10}{|c|}{ Schooling (years) } \\
\hline$<8$ & 115 & 76 & $(66.1)$ & 2.59 & $(2.03,3.30)$ & 0.000 & 2.56 & $(1.97,3.32)$ & 0.000 \\
\hline $8-10$ & 271 & 112 & $(41.3)$ & 1.62 & $(1.26,2.07)$ & 0.000 & 1.59 & $(1.23,2.05)$ & 0.000 \\
\hline$\geq 11$ & 266 & 68 & $(25.6)$ & 1.00 & & & 1.00 & & \\
\hline \multicolumn{10}{|c|}{ Paid employment } \\
\hline No & 228 & 96 & $(42.1)$ & 1.12 & $(0.92,1.36)$ & 0.271 & 0.86 & $(0.71,1.04)$ & 0.119 \\
\hline Yes & 424 & 160 & (37.7) & 1.00 & & & 1.00 & & \\
\hline
\end{tabular}

BMMW: Brazilian monthly minimum wage. 
Table 2. Prevalence, crude and adjusted prevalence ratios (PR) and $95 \%$ confidence intervals for tooth loss in male adolescents from southern Brazil.

\begin{tabular}{|c|c|c|c|c|c|c|c|c|c|}
\hline \multirow{2}{*}{ Variables } & \multirow{2}{*}{$\mathrm{n}$} & \multicolumn{2}{|c|}{ Tooth loss } & \multicolumn{3}{|c|}{ Crude model } & \multicolumn{3}{|c|}{ Adjusted model } \\
\hline & & $\mathrm{n}$ & (\%) & PR & $95 \% \mathrm{Cl}$ & $\mathrm{p}$-value & PR & $95 \% \mathrm{Cl}$ & $p$-value \\
\hline \multicolumn{10}{|c|}{ Mother's schooling (years) } \\
\hline$\leq 5$ & 172 & 23 & (13.4) & 2.77 & $(1.44,5.31)$ & 0.002 & 2.30 & $(1.18,4.50)$ & 0.015 \\
\hline $6-8$ & 184 & 19 & (10.3) & 2.14 & $(1.08,4.22)$ & 0.029 & 1.76 & $(0.86,3.56)$ & 0.119 \\
\hline$>8$ & 269 & 13 & $(4.8)$ & 1.00 & & & 1.00 & & \\
\hline \multicolumn{10}{|c|}{ Family income (BMMW) } \\
\hline$<2$ & 142 & 11 & $(7.7)$ & 0.87 & $(0.44,1.72)$ & 0.697 & 0.57 & $(0.26,1.24)$ & 0.160 \\
\hline $2-3$ & 228 & 25 & $(11.0)$ & 1.24 & $(0.73,2.09)$ & 0.428 & 1.07 & $(0.62,1.86)$ & 0.795 \\
\hline$>3$ & 282 & 25 & (8.9) & 1.00 & & & 1.00 & & \\
\hline \multicolumn{10}{|c|}{ Schooling (years) } \\
\hline$<8$ & 115 & 21 & (18.3) & 3.74 & $(1.94,7.20)$ & 0.000 & 3.28 & $(1.61,6.65)$ & 0.001 \\
\hline $8-10$ & 271 & 27 & $(10.0)$ & 2.04 & $(1.07,3.86)$ & 0.029 & 1.65 & $(0.84,3.21)$ & 0.144 \\
\hline$\geq 11$ & 266 & 13 & $(4.9)$ & 1.00 & & & 1.00 & & \\
\hline \multicolumn{10}{|c|}{ Paid employment } \\
\hline No & 228 & 16 & $(7.0)$ & 0.66 & $(0.38,1.14)$ & 0.138 & 1.20 & $(0.68,2.10)$ & 0.534 \\
\hline Yes & 424 & 45 & $(10.6)$ & 1.00 & & & 1.00 & & \\
\hline
\end{tabular}

BMMW: Brazilian monthly minimum wage.

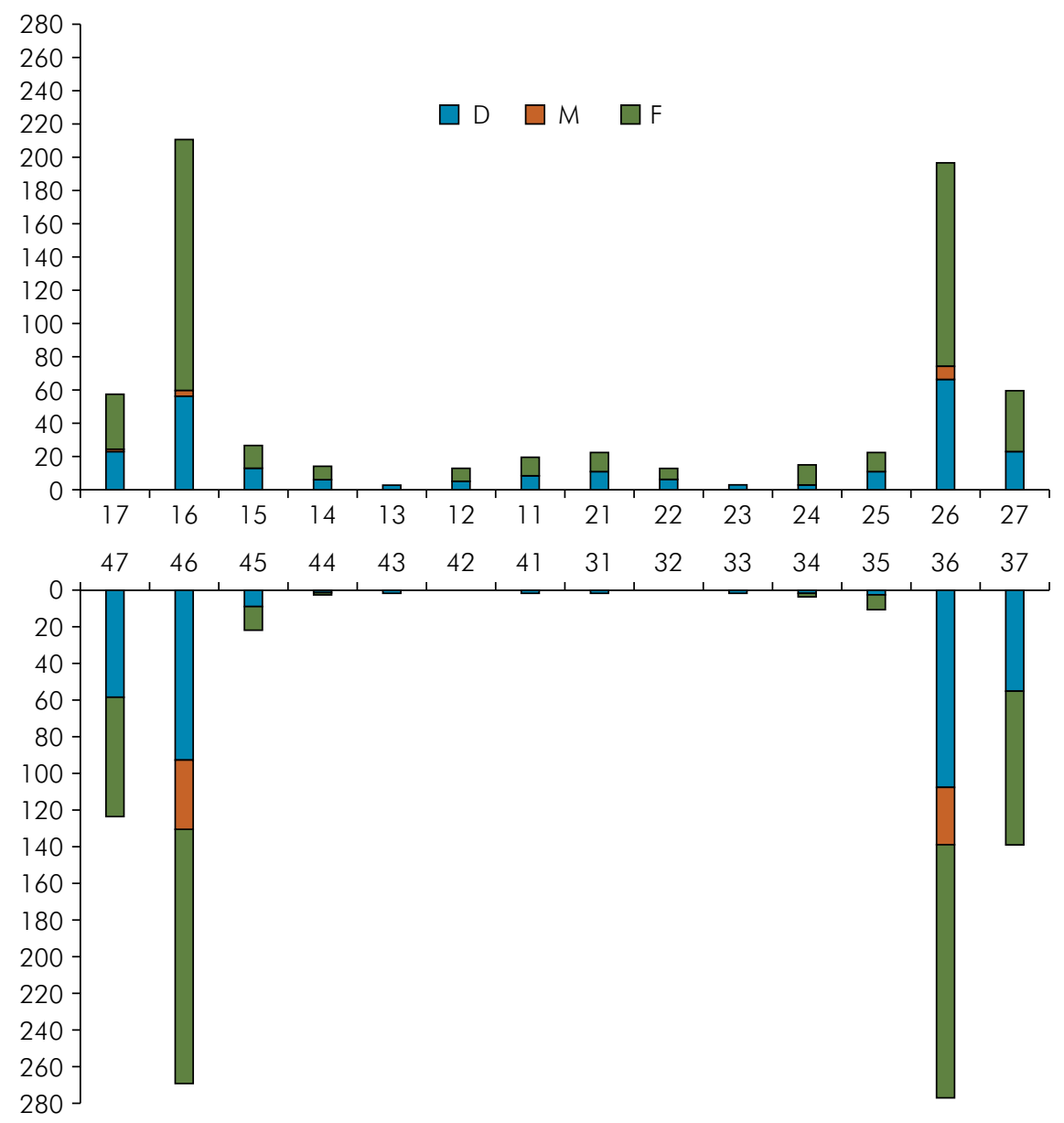

Figure. Distribution of caries experience per tooth. 
Table 3. Distribution of decayed (D), missing (M), and filled (F) components of DMFT index according to tooth group in male adolescents from southern Brazil.

\begin{tabular}{|c|c|c|c|c|c|c|c|c|}
\hline \multirow{2}{*}{ Tooth } & \multicolumn{2}{|c|}{ D } & \multicolumn{2}{|c|}{ M } & \multicolumn{2}{|c|}{$\mathrm{F}$} & \multicolumn{2}{|c|}{ DMFT } \\
\hline & $N$ & (\%) & $\mathrm{N}$ & (\%) & $N$ & (\%) & $N$ & (\%) \\
\hline \multicolumn{9}{|l|}{ Upper } \\
\hline $2 M$ & 45 & (8.0) & 1 & (1.2) & 70 & (7.9) & 116 & $(7.6)$ \\
\hline $1 M$ & 122 & $(21.6)$ & 12 & (14.8) & 274 & (31.0) & 408 & $(26.7)$ \\
\hline $2 \mathrm{PM}$ & 23 & $(4.1)$ & 0 & $(0.0)$ & 25 & (2.8) & 48 & $(3.1)$ \\
\hline $1 P M$ & 9 & $(1.6)$ & 0 & $(0.0)$ & 20 & (2.3) & 29 & (1.9) \\
\hline C & 5 & $(0.9)$ & 0 & $(0.0)$ & 1 & $(0.1)$ & 6 & $(0.4)$ \\
\hline $\mathrm{LI}$ & 12 & $(2.1)$ & 0 & $(0.0)$ & 13 & (1.5) & 25 & (1.7) \\
\hline $\mathrm{Cl}$ & 18 & (3.2) & 0 & $(0.0)$ & 23 & (2.6) & 41 & (2.6) \\
\hline \multicolumn{9}{|l|}{ Lower } \\
\hline $2 M$ & 113 & (20.0) & 0 & $(0.0)$ & 150 & $(17.0)$ & 263 & (17.2) \\
\hline $1 M$ & 201 & $(35.6)$ & 68 & $(84.0)$ & 280 & (31.7) & 549 & (35.9) \\
\hline $2 \mathrm{PM}$ & 11 & (1.9) & 0 & $(0.0)$ & 22 & $(2.5)$ & 33 & $(2.1)$ \\
\hline $1 P M$ & 2 & $(0.4)$ & 0 & $(0.0)$ & 5 & $(0.6)$ & 7 & $(0.5)$ \\
\hline C & 2 & $(0.4)$ & 0 & $(0.0)$ & 0 & $(0.0)$ & 2 & $(0.2)$ \\
\hline LI & 0 & $(0.0)$ & 0 & $(0.0)$ & 0 & $(0.0)$ & 0 & $(0.0)$ \\
\hline $\mathrm{Cl}$ & 2 & $(0.4)$ & 0 & $(0.0)$ & 0 & $(0.0)$ & 2 & $(0.2)$ \\
\hline Total & 565 & $(100.0)$ & 81 & $(100.0)$ & 883 & $(100.0)$ & 1529 & $(100.0)$ \\
\hline
\end{tabular}

\section{Discussion}

The present study provides a panorama of the socioeconomic and intraoral polarization of two clinically important oral health outcomes: untreated dental caries and tooth loss. The main findings were a strong concentration of both outcomes in permanent first molars, and adolescents with low schooling and those of mother's with low schooling were more affected.

Understanding the relationship between socioeconomic level and health indicators continues to be a challenge, with an emphasis on social inequalities and the influence of poverty on health and wellbeing. ${ }^{17,26}$ In the present investigation, both the mother's and the adolescent's schooling were associated with untreated caries and tooth loss. It was not within the scope of this study to investigate how socioeconomic status affects oral health outcomes and therefore the mechanism by which more schooling protects the individual from these outcomes was not identified. However, it is possible that a more educated mother has greater care regarding eating habits and oral hygiene practices in the family setting as well as greater access to, and use of, healthcare services. ${ }^{15,16,27}$ This relationship might be mediated by psychosocial factors of individuals and families with a better socioeconomic status, such as higher perceived seriousness, self-efficacy, social support, and family cohesion. ${ }^{16,23}$ It is likely that the education level of the mother still influenced the oral health of these 18-year-old adolescents.

Adolescent's schooling had a dose-response relationship with occurrence of untreated caries and high effect estimates regarding tooth loss. It is possible that teenagers held back in school or those who drop out of school have characteristics that favor untreated caries and tooth loss, such as worse health behaviors, a lower perception of care need, and difficulty controlling their own health. ${ }^{15,28,29,30}$ Although the prevalence of untreated caries was higher among adolescents with a lower income, this significance was lost after the adjustment for other socioeconomic variables. It is possible that the trajectory of income in families is more strongly associated with untreated dental caries than current income, as demonstrated in a cohort study involving adolescents from southern 
Brazil. ${ }^{18}$ Having paid employment, which could be related to a higher income for the adolescents themselves, was not associated with either of the outcomes investigated.

The different susceptibility of tooth groups to dental caries has been reported elsewhere. ${ }^{21,31,32}$ However, the present study draws attention to the dimension of the polarization of both outcomes, with nearly $90 \%$ of untreated caries on a single tooth group (molars), especially the first molars. Although this polarization may become attenuated over time, it will persist throughout life..$^{21}$ These data point to the need for oral health professionals and services to direct specific prevention and treatment strategies at this tooth group beginning in the early school phase. The polarization of tooth loss in first molars was even stronger, with nearly all missing teeth being from this tooth group (especially lower first molars), which is in agreement with findings described in previous studies. ${ }^{3,33}$ Permanent first molars are often the first to emerge and thus are exposed for a longer period of time than most teeth, but this may only partially explain the greater susceptibility, as those are the most common missing teeth throughout life. ${ }^{21}$ Anatomic characteristics and position in the arch are additional factors related to a greater accumulation of biofilm and food retention and more difficult access to adequate hygiene. $3,32,33,34$

Among the implications of the present findings for policies and programs, the strong association of schooling (adolescent's and mother's) with oral health outcomes underscores the need for strategies that promote education in primary and high school and reduce truancy of adolescents, which has repercussions not only for their own health but also for their future children. More years of education translates into better employment and improved self-care and mother/child health. ${ }^{35}$ Thus, the World Health Organization has emphasized the need for pregnancy prevention policies in adolescence, which is also associated with negative health outcomes in mothers that are perpetuated in their children. ${ }^{36}$

Regarding the implications for administrators, health services, and dentists, primary, secondary, and tertiary prevention protocols should consider the impressive concentration of untreated caries and tooth loss in permanent first molars. The application of sealants, especially in children and adolescents with a low socioeconomic status, is among the proven cost-effective measures. ${ }^{37}$ The effectiveness of resin sealants stands out as one of the measures with the strongest evidence of prevention in oral health, reducing the number of decayed surfaces on permanent first molars by $88 \%$ when applied by ten years of age, which could have a very strong impact on reducing the overall prevalence of caries in adolescents. ${ }^{37,38}$ Other prevention measures directed at schoolchildren at the time of first molars eruption should be encouraged, taught, and supported, such as reduction in sugar intake and effective individualized oral hygiene practices. ${ }^{39,40}$

The present study has limitations that should be considered. The cross-sectional design impedes the establishment of a causal relation. However, mother's schooling, unlike family income, is a stable variable over time and it is plausible that it preceded the outcome, which suggests a protective effect. The sample was composed exclusively of male adolescents and it is difficult to estimate the extent to which this factor may compromise the generalization of the results. However, significant differences in the frequencies of the exposure and outcome variables between sexes are unlikely and estimates would probably be similar in teenage girls.

\section{Conclusion}

The findings of the present study demonstrate a strong polarization of untreated dental caries and tooth loss in permanent first molars of adolescents with a low level of schooling and whose mothers had a low level of schooling. Such findings should be considered when planning and implementing health strategies and policies on both the individual and collective levels.

\section{Acknowledgments}

This study received funds from the following Brazilian funding agency: Coordination for the Advancement of Higher Education Personnel (CAPES) 
Socioeconomic and intraoral polarization of untreated caries and tooth loss among male adolescents

\section{References}

1. Marcenes W, Kassebaum NJ, Bernabé E, Flaxman A, Naghavi M, Lopez A, et al. Global burden of oral conditions in 1990-2010: a systematic analysis. J Dent Res. 2013 Jul;92(7):592-7. https://doi.org/10.1177/0022034513490168

2. Kassebaum NJ, Smith AG, Bernabé E, Fleming TD, Reynolds AE, Vos T, et al. Incidence, and disability-adjusted life years for oral conditions for 195 countries, 1990-2015: a systematic analysis for the global burden of diseases, injuries, and risk factors. J Dent Res. 2017 Apr;96(4):380-7. https://doi.org/10.1177/0022034517693566

3. Susin C, Haas AN, Opermann RV, Albandar JM. Tooth loss in a young population from south Brazil. J Public Health Dent. 2006;66(2):110-5. https://doi.org/10.1111/j.1752-7325.2006.tb02565.x

4. Kassebaum NJ, Bernabé E, Dahiya M, Bhandari B, Murray CJ, Marcenes W. Global burden of severe tooth loss: a systematic review and meta-analysis. J Dent Res. 2014 Jul;93(7 Suppl):20S-8S. https://doi.org/10.1177/0022034514537828

5. Figueiredo DR, Bastos JL, Peres KG. Association of adverse oral health outcomes with socioeconomic inequalities and dental needs in Brazilian adolescents. Cad Saude Publica. 2017 Jun;33(5):e00165415. https://doi.org/10.1590/0102-311x00165415

6. Barboza-Solís C, Porras-Chaverri M, Fantin R. Is tooth loss important when evaluating perceived general health? Findings from a nationally representative study of Costa Rican adults. Community Dent Oral Epidemiol. 2019 Aug;47(4):358-65. https://doi.org/10.1111/cdoe.12466

7. Peres MA, Barbato PR, Reis SC, Freitas CH, Antunes JL. [Tooth loss in Brazil: analysis of the 2010 Brazilian Oral Health Survey]. Rev Saude Publica. 2013 Dec;47 Suppl 3:78-89. Portuguese. https://doi.org/10.1590/S0034-8910.2013047004226

8. Peres KG, Cascaes AM, Leão AT, Côrtes MI, Vettore MV. [Sociodemographic and clinical aspects of quality of life related to oral health in adolescents]. Rev Saude Publica. 2013 Dec;47(3 Suppl 3):19-28. Portuguese. https://doi.org/10.1590/S0034-8910.2013047004361

9. Schwendicke F, Dörfer CE, Schlattmann P, Foster Page L, Thomson WM, Paris S. Socioeconomic inequality and caries: a systematic review and meta-analysis. J Dent Res. 2015 Jan;94(1):10-8. https://doi.org/10.1177/0022034514557546

10. Feldens CA, Ardenghi TM, Dullius AIS, Vargas-Ferreira F, Hernandez PA, Kramer PF. Clarifying the impact of untreated and treated dental caries on oral health-related quality of life among adolescents. Caries Res. 2016;50(4):414-21. https://doi.org/10.1159/000447095

11. Righolt AJ, Jevdjevic M, Marcenes W, Listl S. Global-, regional-, and country-level economic impacts of dental diseases in 2015. J Dent Res. 2018 May;97(5):501-7. https://doi.org/10.1177/0022034517750572

12. Hobdell M, Petersen PE, Clarkson J, Johnson N. Global goals for oral health 2020. Int Dent J. 2003 Oct;53(5):285-8. https://doi.org/10.1111/j.1875-595X.2003.tb00761.x

13. Ministério da Saúde (BR). Secretaria de Atenção à Saúde. Secretaria de Vigilância em Saúde. Pesquisa Nacional de Saúde Bucal: resultados principais. Brasília, DF: Ministério da Saúde; 2012 [cited 2010 Nov 25]. Available from: http://bvsms.saude.gov.br/bvs/ publicacoes/pesquisa_nacional_saude_bucal.pdf

14. FDI World Dental Federation. The challenge of oral disease: a call for global action. The oral health atlas. 2nd ed. Geneva: FDI World Dental Federation; 2015. [cited 2015 Apr 10]. Available from: https://www.fdiworlddental.org/sites/default/files/media/documents/ complete_oh_atlas.pdf

15. Han DH, Khang YH. Lifecourse socioeconomic position indicators and tooth loss in Korean adults. Community Dent Oral Epidemiol. 2017 Feb;45(1):74-83. https://doi.org/10.1111/cdoe.12262

16. Dutra LD, Neves ÉT, Lima LC, Gomes MC, Forte FD, Paiva SM, et al. Degree of family cohesion and social class are associated with the number of cavitated dental caries in adolescents. Braz Oral Res. 2020 Apr;34:e037. https://doi.org/10.1590/1807-3107bor-2020.vol34.0037

17. Peres MA, Macpherson LM, Weyant RJ, Daly B, Venturelli R, Mathur MR, et al. Oral diseases: a global public health challenge. Lancet. 2019 Jul;394(10194):249-60. https://doi.org/10.1016/S0140-6736(19)31146-8

18. Peres MA, Liu P, Demarco FF, Silva AE, Wehrmeister FC, Menezes AM, et al. Income trajectories affect treatment of dental caries from childhood to young adulthood: a birth cohort study. Braz Oral Res. 2018;32(0):e36. https://doi.org/10.1590/1807-3107bor-2018.vol32.0036

19. World Health Organization. Regional Office of Europe. Health 2020: education and health through the life-course. Geneva: World Health Organization; 2015 [cited 2020 Sept 14]. Available from: https://www.euro.who.int/_data/assets/pdf_file/0007/324619/Health2020-Education-and-health-through-the-life-course-en.pdf? ua =1

20. Mejàre I, Axelsson S, Dahlén G, Espelid I, Norlund A, Tranæus S, et al. Caries risk assessment. A systematic review. Acta Odontol Scand. 2014 Feb;72(2):81-91. https://doi.org/10.3109/00016357.2013.822548

21. Broadbent JM, Foster Page LA, Thomson WM, Poulton R. Permanent dentition caries through the first half of life. Br Dent J. 2013 Oct;215(7):E12. https://doi.org/10.1038/sj.bdj.2013.991 
22. Ferreira Zandoná A, Santiago E, Eckert GJ, Katz BP, Oliveira SP, Capin OR, et al. The natural history of dental caries lesions: a 4 -year observational study. J Dent Res. 2012 Sep;91(9):841-6. https://doi.org/10.1177/0022034512455030

23. Torres LH, Zanatta J, Pizolato RA, Grillo CM, Frias AC, Sousa ML. Reasons related to tooth loss among adolescents in São Paulo, Brazil. Braz J Oral Sci. 2014 Jan-Mar;13(1):37-42. https://doi.org/10.1590/1677-3225v13nla08

24. Feldens CA, Dullius AIS, Kramer PF, Scapini A, Busato AL, Vargas-Ferreira F. Impact of malocclusion and dentofacial anomalies on the prevalence and severity of dental caries among adolescents. Angle Orthod. 2015 Nov;85(6):1027-34. https://doi.org/10.2319/100914-722.1

25. World Health Organization - WHO. Oral health surveys: basic methods. 4th ed. Geneva: 1997 [cited 2020 Apr 16]. Available from: https://apps.who.int/iris/bitstream/handle/10665/41905/9241544937.pdf? sequence=1\&isAllowed=y

26. Celeste RK, Eyjólfsdóttir HS, Lennartsson C, Fritzell J. Socioeconomic life course models and oral health: a longitudinal analysis. J Dent Res. 2020 Mar;99(3):257-63. https://doi.org/10.1177/0022034520901709

27. Fontanini H, Marshman Z, Vettore M. Social support and social network as intermediary social determinants of dental caries in adolescents. Community Dent Oral Epidemiol. 2015 Apr;43(2):172-82. https://doi.org/10.1111/cdoe.12139

28. Harris RV, Pennington A, Whitehead M. Preventive dental visiting: a critical interpretive synthesis of theory explaining how inequalities arise. Community Dent Oral Epidemiol. 2017 Apr;45(2):120-34. https://doi.org/10.1111/cdoe.12268

29. Alves LS, Susin C, Damé-Teixeira N, Maltz M. Tooth loss prevalence and risk indicators among 12-year-old schoolchildren from South Brazil. Caries Res. 2014;48(4):347-52. https://doi.org/10.1159/000357226 PMID:24603282

30. Paula JS, Ambrosano GM, Mialhe FL. The impact of social determinants on schoolchildren's oral health in Brazil. Braz Oral Res. 2015 Ago;29(1):0098. https://doi.org/10.1590/1807-3107BOR-2015.vol29.0098

31. Batchelor PA, Sheiham A. Grouping of tooth surfaces by susceptibility to caries: a study in 5-16 year-old children. BMC Oral Health. 2004 Oct;4(1):2. https://doi.org/10.1186/1472-6831-4-2

32. Shaffer JR, Polk DE, Feingold E, Wang X, Cuenco KT, Weeks DE, et al. Demographic, socioeconomic, and behavioral factors affecting patterns of tooth decay in the permanent dentition: principal components and factor analyses. Community Dent Oral Epidemiol. 2013 Aug;41(4):364-73. https://doi.org/10.1111/cdoe.12016

33. Barbato PR, Peres MA. Tooth loss and associated factors in adolescents: a Brazilian population-based oral health survey. Rev Saude Publica. 2009 Feb;43(1):13-25. https://doi.org/10.1590/S0034-89102009000100003

34. Llena C, Calabuig E, Sanz JL, Melo M. Risk factors associated with carious lesions in permanent first molars in children: a seven-year retrospective cohort study. Int J Environ Res Public Health. 2020 Feb;17(4):1421. https://doi.org/10.3390/ijerph17041421

35. Unesco. Education transform lives. Paris; 2020. [cited 2020 Apr 23]. Available from: https://en.unesco.org/themes/education

36. World Health Organization - WHO. Adolescent pregnancy. 2020 Jan 31 [cited 2020 Apr 22]. Available from: https://www.who.int/ news-room/fact-sheets/detail/adolescent-pregnancy

37. Espinoza-Espinoza G, Corsini G, Rojas R, Mariño R, Zaror C. The cost-utility of school-based first permanent molar sealants programs: a Markov model. BMC Oral Health. 2019 Dec;19(1):293. https://doi.org/10.1186/s12903-019-0990-3

38. Ahovuo-Saloranta A, Forss H, Walsh T, Nordblad A, Mäkelä M, Worthington HV. Pit and fissure sealants for preventing dental decay in permanent teeth. Cochrane Database Syst Rev. 2017 Jul;7(7):CD001830. https://doi.org/10.1002/14651858.CD001830.pub5

39. Moynihan PJ, Kelly SA. Effect on caries of restricting sugars intake: systematic review to inform WHO guidelines. J Dent Res. 2014 Jan;93(1):8-18. https://doi.org/10.1177/0022034513508954

40. Jepsen S, Blanco J, Buchalla W, Carvalho JC, Dietrich T, Dörfer C, et al. Prevention and control of dental caries and periodontal diseases at individual and population level: consensus report of group 3 of joint EFP/ORCA workshop on the boundaries between caries and periodontal diseases. J Clin Periodontol. 2017 Mar;44 Suppl 18:S85-93. https://doi.org/10.1111/icpe.12687 